\title{
Optimal Operation of a Single Unit with an Adjustable Blade in an Interbasin Water Transfer Pumping Station Based on Successive Approximation Discretization for Blade Angle
}

\author{
Yi Gong $\left(\mathbb{D},{ }^{1}\right.$ Jilin Cheng, ${ }^{1}$ Li Che, ${ }^{2}$ Liang Wang, ${ }^{1}$ Zaiyang Chen, ${ }^{1}$ and Yongfeng Chen ${ }^{3}$ \\ ${ }^{1}$ College of Hydraulic Science and Engineering, Yangzhou University, Yangzhou 225009, China \\ ${ }^{2}$ River and Lake Management Office of Hongze District, Huai'an 223100, China \\ ${ }^{3}$ Liyang Water Conservancy Bureau, Liyang 213300, China \\ Correspondence should be addressed to Yi Gong; gongyi_8@163.com
}

Received 13 October 2020; Revised 4 January 2021; Accepted 15 March 2021; Published 23 March 2021

Academic Editor: Yong Zhu

Copyright ( 2021 Yi Gong et al. This is an open access article distributed under the Creative Commons Attribution License, which permits unrestricted use, distribution, and reproduction in any medium, provided the original work is properly cited.

In the mathematical model of the optimal operation of a single pump unit with a fully adjustable blade in the Chinese South-to-North Water Diversion Project, the decision variable, namely, blade angle, was uniformly dispersed in its feasible region in a fixed step size in consideration of the requirements of the pumping head and matching motor power. 1D dynamic programming was applied to solve the original model. When the obtained blade for each time period was set as the middle reference value and the discrete region of the blade was reduced to two times of the step size in the previous time, the blade angle was correspondingly reduced and dispersed in this new discrete region, thus eliminating unnecessary optimization space. Then, 1D dynamic programming was applied again to optimize the blade angle of the single pump unit further. After a series of successive approximation discretization of the blade angle and corresponding solutions of the obtained mathematical model, the optimization process was considered completed when the given control precision met the requirement. A case study showed that under typical operating conditions, the total cost saving percentage of water pumping quantity reached $0.048 \%-0.463 \%$, with an average saving rate of $0.192 \%$. The actual total water pumping quantity of the single unit decreased by $2153 \mathrm{~m}^{3}$ on the average. The proposed discretization method exerted a better optimization effect and needed a smaller computational amount compared with traditional one-time uniform discretization in the original feasible region of the blade angle.

\section{Introduction}

Pump performance has an important influence on realizing an efficient pump operation. Given the extensive application of pumps in different fields, including hydraulic engineering, chemical industry, manufacturing, and environmental protection $[1,2]$, studies on the performance of centrifugal [3,4], axial flow [5], sewage [6], submersible well [7], fully tubular [8], and multistage $[9,10]$ pumps have been conducted using various advanced methods and technologies, such as numerical simulation [11], experimental analysis, and intelligent fault diagnosis $[12,13]$. Focus should also be placed on the operating process of pump units because, sometimes, actual working conditions may exceed the designed range, which means that pump performance is effectively influenced by external conditions with frequent change. Therefore, the optimal operation of pump units should be studied in consideration of various influencing factors to reduce energy consumption effectively during the operating process. Pumps in the Eastern Route of the Chinese South-to-North Water Diversion Project are typical examples.

After the completion and implementation of the first phase of the project, extensive comprehensive benefits have been achieved in terms of alleviating the uneven distribution of water resources in time and space $[14,15]$. Studying the optimal operation methods for pumping stations has become a research hotspot because of the high energy consumption of such stations during operation. Scholars at home and abroad have proposed different types of 
optimization models for pumping stations, the most common of which is the optimization model with the minimum power cost or energy consumption as the objective function [16-19]. The adjustable operation mode of pump units, such as blade adjustment or variable speed control, makes the optimization model solution feasible [20]. Price and Ostfeld [21] used an iterative linear discrete pump scheduling algorithm with linear programming to optimize the operation of a water system. Jiang et al. [22] solved an optimization model with the decomposition coordination method, which alleviates the time-space contradiction of water supply allocation between pumping stations at all levels and significantly reduces the water shortage of the system. Gong and Cheng [23] applied an experimental optimization method for a large-scale system to optimize the operation of a pumping station with adjustable blade and variable speed and obtained the unit power cost under different operation loads and daily average heads. Gong et al. [24] proposed a decomposition-dynamic programming aggregation method that can solve the mathematical model of a single pumping station with different types of pump units installed. Makaremi et al. [25] proposed a multiobjective optimization method that uses NSGA-II coupled with EPANET to optimize the energy cost and number of pump switches. Dou et al. [26] constructed a multiobjective optimization model for water trading by taking the Middle Route of China's South-to-North Water Diversion Project as the research object; then, they used nondominated sorting genetic algorithms to solve this optimization model and presented a feasible water trading scheme for the water-receiving area of Henan Province. Bagloee et al. [27] employed a mixed method with an optimized regression model to study water pumps. This method can be extended to variable speed pumps to improve efficiency and reduce maintenance costs.

With the continuous progress of computer technology, artificial intelligence algorithms with random sampling characteristics, such as particle swarm optimization algorithm [28], ant colony optimization algorithm [29], artificial neural network [30], and genetic algorithm [31], have been widely applied to the optimization issues of pump or pumping station operation. Several hybrid algorithms with combinations of different algorithms' advantages have also been developed for the operation optimization of pumping stations. RasoulzadehGharibdousti et al. [32] developed a mixed scheme of nonlinear programming and genetic algorithm to solve the optimal design and operation of an irrigation pumping station and further optimized the minimum annual investment cost and annual operation cost of the pumping station. Bohórquez et al. [33] proposed an improved genetic algorithm that was realized through a combination of GA-EPANET and determined the best operation mode of water pumping. Bagirov et al. [34] obtained a scheduling scheme for minimizing the operation cost of a pumping station in a water supply system by proposing a scheduling method based on a combination of grid search and the Hooke-Jeeves mode search method. Kougias and Theodossiou [35] introduced MO-HSA and Poly-HAS for the optimization issue of pumping scheduling to alleviate the peak power demand and reduce the maintenance cost of pump units.
Dynamic programming has been widely applied in hydraulic structure optimization [36], joint operation optimization of reservoir systems [37, 38], power system optimization [39], and water pumping stations [40]. Dynamic programming theory can be used to solve the mathematical model of optimal operation for a single pump unit with characteristics of stage separability. The main problem is that the discrete step size and number of decision variables in each divided time period directly affect the accuracy and efficiency of the model solution results. With the operation of a single pump unit with an adjustable blade as an example, achieving the ultimate foothold of optimal operation of the pump unit entails providing the management department with an optimization scheme of the blade angle in each time period divided by a given water diversion period. Owing to the fact that most pumping stations in the Eastern Route of the Chinese South-to-North Water Transfer Project are equipped with adjustable-blade units with hydraulic pressure adjustment, obtaining an arbitrary blade angle in each divided time period for realizing the optimal operation of pump units is theoretically feasible. Considering that each blade angle corresponds to a single set of performance curves of pump units, a large amount of workload is needed for the performance curve fitting of all discrete blade angles, leading to a decline in model solution efficiency. With a discrete control method of blade angle for a single unit, high-precision optimization results can be obtained quickly and effectively, and an effective calculation means can be provided for further solving the mathematical model of a single pumping station with multiple units or even pumping stations.

On the basis of these considerations, a dynamic programming method for an optimal operation model of a single pump unit based on successive approximation discretization of the blade angle is developed to determine the minimum power cost of water pumping and the corresponding optimal operation scheme of the pump unit in a given pumping period under factors of varying daily pumping head and water pumping amount. With this method, further improvement of the solution accuracy and efficiency of the optimal operation model can be obtained.

\section{Modeling}

2.1. Optimal Operation Model for a Single Pump Unit with Adjustable Blade. In accordance with [17], a mathematical model of optimal operation for a single pump unit with a fully adjustable blade was constructed with the aim of minimizing the energy cost of the unit. The constructed model takes the blade angle in each divided time period as a decision variable in consideration of constraints, including total water amount, matched motor power, and startupshutdown times of the pump unit in one day:

Objective function $f=\min \sum_{i=1}^{\mathrm{SN}} \frac{\rho \cdot g \cdot Q_{i}\left(\theta_{i}\right) \cdot H_{i}}{\eta_{z i}\left(\theta_{i}\right) \cdot \eta_{\text {mot }} \cdot \eta_{\mathrm{int}}} \cdot \Delta T_{i} \cdot P_{i}$,

Total water amount constraint $\sum_{i=1}^{\mathrm{SN}} \mathrm{Q}_{i}\left(\theta_{i}\right) \cdot \Delta T_{i} \geq \mathrm{We}$, 
Motor power constraint $N_{i}\left(\theta_{i}\right) \leq N_{0}$,

Startup - shutdown Times constraint $K \leq K_{0}$,

where $f$ represents the minimal electric cost of a single pump unit in a total water pumping period (RMB), $S N$ represents the number of periods divided by the total period, $\rho$ represents the density of water $\left(1000 \mathrm{~kg} / \mathrm{m}^{3}\right)$, and $g$ represents the acceleration of gravity $\left(9.81 \mathrm{~m} / \mathrm{s}^{2}\right) . H_{i}, \Delta T_{i}$, and $P_{i}$, respectively, represent the pumping head $(\mathrm{m})$, length of the divided time period $(h)$, and peak-valley electricity price (RMB/kW.h) of the single pump unit in the $i$-th time period. $W_{e}$ represents the requested total water quantity (TWPQ) of a single pump unit in the total water pumping period $\left(\mathrm{m}^{3}\right)$. $Q_{i}\left(\theta_{i}\right), \eta_{z, i}\left(\theta_{i}\right)$, and $N_{i}\left(\theta_{i}\right)$, respectively, represent the flow rate $\left(\mathrm{m}^{3} / \mathrm{s}\right)$, pump efficiency, and actual motor power of the pump unit in the $i$-th time period corresponding to blade angle $\theta_{i} \cdot \eta_{\text {mot }}, \eta_{\text {int }}$, and $N_{0}$, respectively, represent motor efficiency, transmission efficiency, and matched motor power $(\mathrm{kW}) . \eta_{\text {mot }}$ remains $94 \%$ when the motor load is over $60 \%$, and $\eta_{\text {int }}$ can be viewed as $100 \%$ when the unit adopts a direct connection. $K$ represents the time constraint of starting up and shutting down the pump unit in a total operating period. Starting-up and shutting-down times should not exceed the maximum number $K_{0}$ considering that large-scale pump units should not be started up nor shut down frequently in a total water pumping period.

2.2. Model Solution Method. The constructed model $[(1)-(4)]$ is a typical $1 \mathrm{D}$ dynamic programming model that takes $i(i=1,2, \ldots, \mathrm{SN})$ as a stage variable, blade angle $\theta_{i}$ of the pump unit in each divided time period as the decision variable, and TWPQ in total $i$ stages as the state variable $\lambda$. When the decision variable of each period is dispersed at a certain step in a feasible region, the optimal blade angle of each time period and the corresponding minimum cost of water pumping can be obtained by applying the 1D dynamic programming method to solve the original model according to [17]. During programming solution, the startup-shutdown time constraint can be easily regarded as a determined treatment in the stage of the optimization search process.

Notably, when the blade angle is evenly dispersed in each time period, rational determination of the discrete step exerts a significant effect on the obtained objective function value of the model. An extremely large discrete step is beneficial for reducing the optimization calculation workload because of the small number of discrete blade angles, but it leads to a small selection space of the blade angle during the optimization process of model solving; hence, the optimization benefit cannot be effectively maximized. On the contrary, an extremely small discrete step size of the blade angle is helpful for obtaining improved optimization efficiency, but the optimization workload increases greatly; specifically, both the $1 \mathrm{D}$ dynamic programming calculation workload and the fitting workload of the performance characteristic curves of $H \sim Q$ and $\eta_{\mathrm{z}} \sim Q$ corresponding to each blade angle are increased.
With the considerations given above, this study focuses on a reasonable and highly efficient discrete method of decision variables. By adopting the $1 \mathrm{D}$ dynamic programming method based on successive approximation discretization of the blade angle for $s$ single pump unit in each divided time period to solve the constructed model, the integration of high model solution accuracy and low optimization calculation workload can be realized.

\subsubsection{D Dynamic Programming of the Original Model.} For the original model [(1)-(4)], average pumping head $H_{i}$ $(i=1,2, \ldots, \mathrm{SN})$ is given in each divided time period. In consideration of the requirements of motor matching power $N_{0}$, the setting angle of the pump in each time period can be uniformly dispersed in the feasible region at a certain step size. During this process, the lower boundary of the feasible region corresponds to the minimum blade angle $\theta_{i, \min }$, and the upper boundary is the maximum blade angle $\theta_{i, \max }$ at which the pump unit should not exceed the requirements of matched motor power $N_{0}$. After the discrete step is taken as $S_{0}$ in the feasible region, the $1 \mathrm{D}$ dynamic programming method can be applied to solve the model (1)-(4) in accordance with [17] and to obtain the optimal blade angle $\theta_{i}^{1}$ $(i=1,2, \ldots, \mathrm{SN})$ during optimal operation along with the corresponding minimum operation cost of water pumping $f^{1}$.

\subsubsection{Dynamic Programming Based on Successive Approxi- mation Discretization for Blade Angle}

(1) On the basis of Section 2.2.1, the obtained optimal blade angle $\theta_{i}^{1}(i=1,2, \ldots, \mathrm{SN})$ for each divided time period is further dispersed. The concrete steps are as follows. The discrete width of the blade angle in each period should be set as $\Psi_{1}=2 S_{0}$ to ensure that the discrete range of the blade angle in the second time of optimization will not jump out of the two adjacent discrete values before and after the blade placement angle in the last optimization. This discretization method can effectively reduce unnecessary calculation workload during the second time of optimization. On the basis of the optimized discrete domain, the discrete step is further set as $S_{1}\left(S_{1}<S_{0}\right)$. Notably, given that the blade angle in the last optimization $\theta_{i}^{1}$ $(i=1,2, \ldots, \mathrm{SN})$ is different from the others in the divided time period, the discrete domain of the blade angle also differs from others in the time period during this optimization process. Therefore, the discrete domain in each divided time period must be determined and set. After fitting the performance curve of each new discrete blade angle, the $1 \mathrm{D} d \mathrm{dy}$ namic programming method can be applied again to solve the original model and obtain a new series of optimal blade angles $\theta_{i}^{2}(i=1,2, \ldots, \mathrm{SN})$ for each divided time period along with the corresponding minimum operation cost of water pumping $f^{2}$.

(2) On the basis of Step (1), the obtained optimal blade angle $\theta_{i}^{2}(i=1,2, \ldots, \mathrm{SN})$ in each time period is 
further dispersed. Similarly, the width of the discrete region of the blade angle in each period is set as $\Psi_{2}=2 S_{1}$ with a discrete step of $S_{2}\left(S_{2}<S_{1}\right)$. After fitting the performance curve of each new discrete blade angle, the 1D dynamic programming method is used to solve the original model and obtain a new series of optimal blade angles $\theta_{i}^{3}(i=1,2, \ldots, \mathrm{SN})$ in each time period along with the corresponding minimum operation cost of water pumping $f^{3}$.

(3) With the successive approximation method for blade angle discretization, a series of $1 \mathrm{D}$ dynamic programming is applied to solve the original model until the given iterative control accuracy $\mathcal{E}$ meets the inequality $\left|f^{m-1}-f^{m} / f^{m-1}\right|$. The obtained $f^{m}$ can be regarded as the minimum optimal operation cost of the single pump unit with full-adjustment blades and optimal blade angle $\theta_{i}^{m}(i=1,2, \ldots, \mathrm{SN})$.

The following points should be noted.

(1) With the increase in the number of successive approximation times, the discrete width of the blade angle in each divided time period is gradually reduced. By reducing the discrete step size (i.e., $S_{m-1}<S_{m-2}<\ldots<S_{1}<S_{0}$ ), the optimal blade angle with high model solution accuracy can be obtained, while the discrete number of decision variables remains approximately the same as the one in the other successive approximation stages.

(2) Blade angle is affected by the relevant factors of model solution, such as peak-valley electricity prices or TWPQ with non-full load. When the blade angle of a certain or several time periods obtained from the second time of optimization solution exists at the upper (or lower) boundary of the feasible discrete region, the blade angle in that period (or those periods) does not need to be further discretized in the next instance of approximation. Through this treatment, the model solution workload can be further reduced while ensuring the accuracy of model solution.

A diagram of successive approximation discretization for blade angles is shown in Figure 1 for the case of five divided time periods with three successive approximation discretization instances.

\section{Results and Discussion}

3.1. Basic Situation of the Study Case. The No. 4 Huai'an Pumping Station is one of the second-stage pumping stations in the Eastern Route of the Chinese South-to-North Water Transfer Project. It is installed with four vertical axialflow pumps with fully adjustable blades. The design parameters of the pump unit are as follows: $150 \mathrm{r} / \mathrm{min}$ rated speed, $0^{\circ}$ rated blade angle, $2900 \mathrm{~mm}$ impeller diameter, $33.4 \mathrm{~m}^{3} / \mathrm{s}$ flow rate, $4.18 \mathrm{~m}$ designed pumping head, and $2240 \mathrm{~kW}$ matched motor power. The blade can be fully regulated by hydraulic pressure with an adjustment range of $-4^{\circ}$ to $+4^{\circ}$.
3.2. Results and Analysis under Typical Operation Conditions. With the single unit of No. 4 Huai' an Pumping Station as the study case, four typical daily average heads of 3.13, 3.53, 4.13, and $4.53 \mathrm{~m}$ were selected from the designed net pumping range of $3.13-5.33 \mathrm{~m}$. Four typical water pumping loads of $110 \%, 105 \%, 100 \%$, and $90 \%$ were selected as TWPQ of the single pump unit. The selected typical daily average heads and operating loads were combined into several typical operating conditions, which were then used to perform a convenient analysis. Additionally, the operating load (e.g., $110 \%$ load) was defined as the water pumping quantity (110\% corresponding to $110 \%$ load) while operating under a constant designed blade angle of $0^{\circ}$ and rated speed of $150 \mathrm{r} /$ $\min$ for $24 \mathrm{~h}$ at the given daily average head. The startupshutdown time constraint $K_{0}$ was set to 2 in consideration of the fact that large-scale pump units should not be frequently started up nor shut down. Afterward, in consideration of peak-valley electricity prices [17], 1D dynamic programming optimization based on successive approximation discretization of the blade angle was applied to solve the model.

3.2.1. Analysis of Optimal Achievements. Table 1 shows the TWPQ, minimal operation cost (MOC), and corresponding unit cost of TWPQ for daily operation (UMOC) for each typical operating condition obtained by means of $1 \mathrm{D}$ dynamic programming optimization based on successive approximation discretization of the blade angle.

Table 1 indicates that with the increase in the daily average head and water pumping load, the actual TWPQ, MOC, and corresponding UMOC presented increasing trends. This result is in line with the basic logic due to the increasing energy consumption of unit operation with TWPQ and daily average head.

Under several specific operation conditions given by a certain daily average head and operation load, two adjacent optimization results are sometimes consistent, and this may include the following two cases:

(1) If the optimization result obtained from the second time is similar to the one obtained from the first time, this means that the discrete domain and step size have not been reasonably set in the second time of dispersion; hence, a third (or more) optimization is required (e.g., the typical working condition with a daily average head of $3.13 \mathrm{~m}$ and $100 \%$ load shown in Table 1).

(2) If two adjacent optimization results are consistent after the second time of optimization, this means that under this operating condition, the obtained optimization result has already achieved the optimization goal; that is, the optimization result has met the accuracy requirement of $\varepsilon$ (e.g., the typical working condition with a daily average head of $3.53 \mathrm{~m}$ and 105\% load shown in Table 1).

3.2.2. Analysis of Successive Approximation Optimization Results. On the basis of the analysis and comparison of results in Table 1, three indexes for reducing amplitude, 


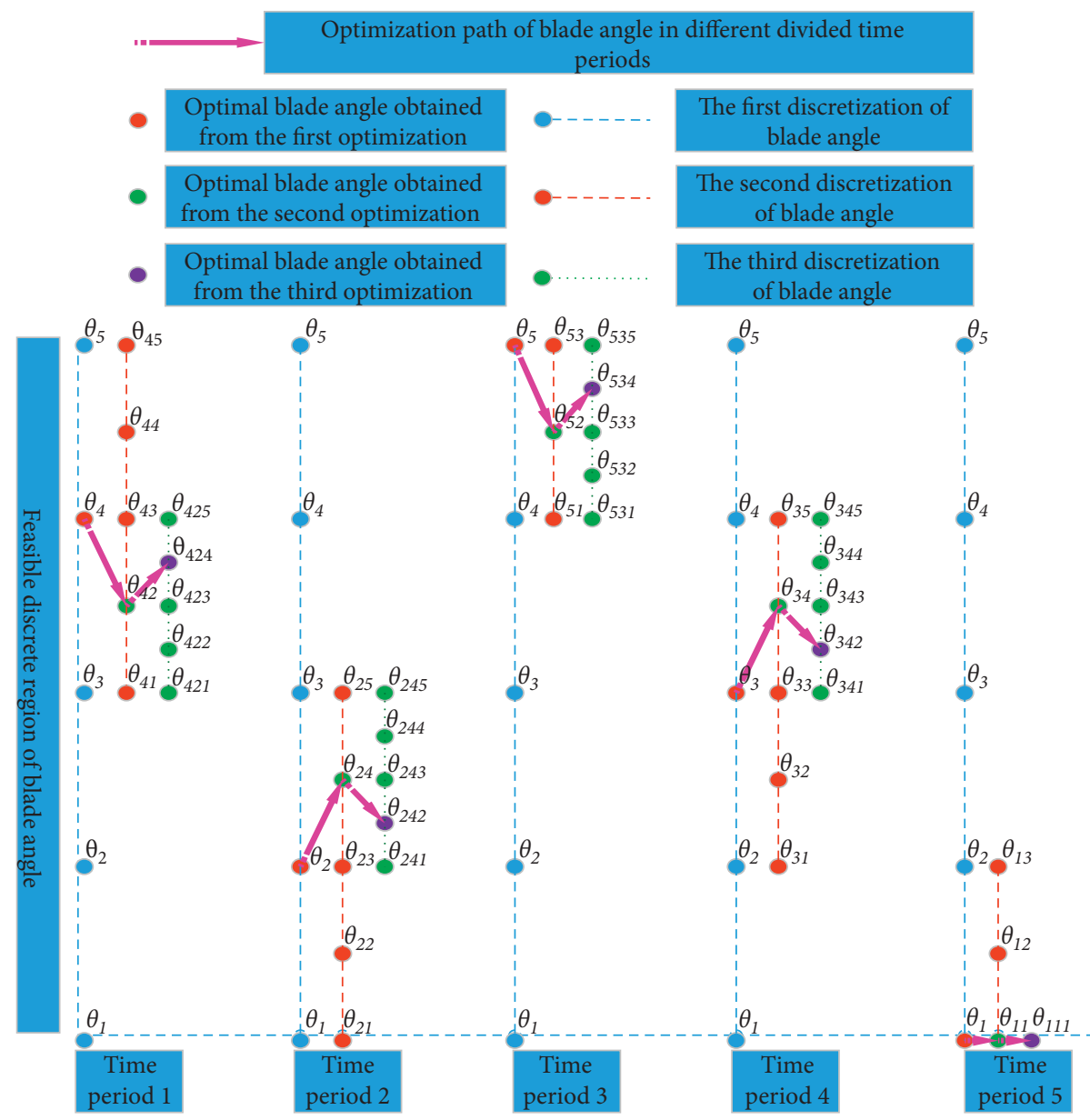

FIGURE 1: Diagram of successive approximation discretization for blade angles.

TABLE 1: Summary of optimal operation results under typical operating conditions.

\begin{tabular}{|c|c|c|c|c|c|c|}
\hline $\begin{array}{l}\text { Daily average } \\
\text { head }(\mathrm{m})\end{array}$ & $\begin{array}{c}\text { Operation load } \\
(\%)\end{array}$ & $\begin{array}{l}\text { Target TWPQ } \\
\qquad\left(10^{4} \mathrm{~m}^{3}\right)\end{array}$ & $\begin{array}{c}\text { Successive approximation } \\
\text { number }\end{array}$ & $\begin{array}{l}\text { Actual TWPQ } \\
\qquad\left(\mathrm{m}^{3}\right)\end{array}$ & $\begin{array}{l}\text { MOC } \\
\text { (RMB) }\end{array}$ & $\begin{array}{c}\text { UMOC } \\
\left(\mathrm{RMB} \cdot 10-{ }^{4} \mathrm{~m}^{-3}\right)\end{array}$ \\
\hline \multirow{9}{*}{3.13} & \multirow{3}{*}{100} & \multirow{3}{*}{315.5} & 1 & 3159592 & 25761.52 & 81.534 \\
\hline & & & 2 & 3159592 & 25761.52 & 81.534 \\
\hline & & & 3 & 3157493 & 25737.59 & 81.513 \\
\hline & \multirow{3}{*}{105} & \multirow{3}{*}{331.3} & 1 & 3318423 & 27455.71 & 82.737 \\
\hline & & & 2 & 3318655 & 27432.83 & 82.662 \\
\hline & & & 3 & 3316058 & 27394.42 & 82.611 \\
\hline & \multirow{3}{*}{110} & \multirow{3}{*}{347.1} & 1 & 3475580 & 30622.17 & 88.107 \\
\hline & & & 2 & 3474629 & 30529.6 & 87.864 \\
\hline & & & 3 & 3473636 & 30480.26 & 87.747 \\
\hline \multirow{9}{*}{3.53} & \multirow{3}{*}{100} & \multirow{3}{*}{307.1} & 1 & 3076763 & 26962.46 & 87.633 \\
\hline & & & 2 & 3073519 & 26915.20 & 87.571 \\
\hline & & & 3 & 3073518 & 26905.19 & 87.539 \\
\hline & \multirow{3}{*}{105} & \multirow{3}{*}{322.4} & 1 & 3226322 & 28678.68 & 88.890 \\
\hline & & & 2 & 3226555 & 28660.30 & 88.826 \\
\hline & & & 3 & 3226555 & 28660.30 & 88.826 \\
\hline & \multirow{3}{*}{110} & \multirow{3}{*}{337.8} & 1 & 3382865 & 31977.66 & 94.528 \\
\hline & & & 2 & 3382865 & 31977.66 & 94.528 \\
\hline & & & 3 & 3382644 & 31962.37 & 94.489 \\
\hline
\end{tabular}


TABle 1: Continued.

\begin{tabular}{|c|c|c|c|c|c|c|}
\hline $\begin{array}{l}\text { Daily average } \\
\text { head }(\mathrm{m})\end{array}$ & $\begin{array}{c}\text { Operation load } \\
(\%)\end{array}$ & $\begin{array}{l}\text { Target TWPQ } \\
\left(10^{4} \mathrm{~m}^{3}\right)\end{array}$ & $\begin{array}{c}\text { Successive approximation } \\
\text { number }\end{array}$ & $\begin{array}{l}\text { Actual TWPQ } \\
\left(\mathrm{m}^{3}\right)\end{array}$ & $\begin{array}{c}\text { MOC } \\
(\mathrm{RMB})\end{array}$ & $\begin{array}{c}\text { UMOC } \\
\left(\mathrm{RMB} \cdot 10-{ }^{4} \mathrm{~m}^{-3}\right) \\
\end{array}$ \\
\hline \multirow{6}{*}{4.13} & \multirow{4}{*}{100} & \multirow{3}{*}{293.5} & 1 & 2936932 & 28693.26 & 97.698 \\
\hline & & & 2 & 2936891 & 28677.15 & 97.645 \\
\hline & & & 3 & 2936844 & 28658.29 & 97.582 \\
\hline & & \multirow{3}{*}{308.2} & 1 & 3092250 & 30704.30 & 99.294 \\
\hline & \multirow[t]{2}{*}{105} & & 2 & 3085541 & 30633.32 & 99.280 \\
\hline & & & 3 & 3084177 & 30601.35 & 99.220 \\
\hline \multirow{2}{*}{4.53} & \multirow{2}{*}{90} & \multirow{2}{*}{255.3} & 1 & 2556365 & 25854.82 & 101.139 \\
\hline & & & 2 & 2554791 & 25810.26 & 101.027 \\
\hline
\end{tabular}

$\mathrm{A} \%$ load refers to A\% of the TWPQ of the single pump unit operating at a designed blade angle of $0^{\circ}$ and rated speed of $150 \mathrm{r} / \mathrm{min}$ for $24 \mathrm{~h}$ under the daily average head.

namely, MOC, TWPQ, and UMOC, under each combination of daily average head and water pumping load were compared with the result of the first optimization, as shown in Table 2.

Table 2 indicates that under the various operating conditions, after implementing the optimization step by step, the total cost of the saving percentage of TWPQ was $0.048 \%-0.463 \%$, with an average saving rate of $0.192 \%$, compared with the results of the first time of optimization. The actual TWPQ of the single unit was reduced by $2153 \mathrm{~m}^{3}$ on the average. The reduction percentage of UMOC was $0.027 \%-0.408 \%$, with an average reduction rate of $0.123 \%$. Although these optimization effects are not significant enough, considering that the comparison reference is the result obtained from the first time of optimization that was already in an optimal operation mode, the optimization benefit can reach more than $7 \%$ compared with the working condition with the designed blade angle and rated speed for the single pump unit [24]. The absolute value of energy cost saving will be large if we consider the joint operation of multiple units of a single pumping station or parallel pumping stations and even the long-distance water transfer project with a long operating period.

In Table 2, the actual total water pumping reduction is a negative value under typical working conditions with a daily average head of $3.53 \mathrm{~m}$ and $105 \%$ load because the optimal operation model takes the MOC of water pumping of the single pump unit as the objective function; this can possibly lead to a reduction in the total cost if the actual total water pumping increases due to the influence of peak-valley electricity prices.

3.2.3. Optimization Process of Successive Approximation for Blade Angles. Three typical working conditions (daily average head of $3.13 \mathrm{~m}$ with $100 \%$ load, daily average head of $4.13 \mathrm{~m}$ with $105 \%$ load, and daily average head of $4.53 \mathrm{~m}$ with $90 \%$ load) were selected as typical cases. The obtained optimal operation schemes based on successive approximation discretization of the blade angle are shown in Table 3. Among the typical working conditions, the one with a typical head of $3.13 \mathrm{~m}$ and $110 \%$ load is shown in Figure 2.

Table 3 illustrates that in the process of successive approximation of the blade angle, several of the obtained blade angles in the optimization scheme were adjusted in several divided time periods compared with that in the previous optimization with the treatment of reducing the discrete domain and discrete step of the blade angle to obtain an improved objective value. According to the peak-valley electricity prices divided in one day and the corresponding time length of each divided time period [17] combined with Figure 2, the adjustment of blade angle was mainly located in the peak electricity price period (periods 1, 2, 6, and 7) and the no-peak-valley electricity price period (period 3) in the successive approximation optimization processes, which indicates that we should pay attention to the optimal correction of the blade angle when operating in periods of peak electricity price and no-peak-valley electricity to obtain an enhanced optimization operation benefit. Special attention should also be paid to the optimal discretization control of blade angles in these time periods.

3.2.4. Operating with Multiple Pump Units in an Annual Water Pumping Period. In accordance with the calculation results of the optimal daily operation of the single pump unit, the saving amplitude parameters of the joint optimal operation of the single pump unit and the single pumping station with three pump units (including MOC, TWPQ, and UMOC) under each combination of daily average head and water pumping load are shown in Table 4 in comparison with the first optimization results; here, the entire water transferring period covered 10 days, and 6 times of water transfer were applied in an entire year.

Table 4 indicates that the actual TWPQ of optimal operation for the single pumping station with three pump units installed under each combination of daily average head and water pumping load could reach a reduction from thousands to tens of thousands (even more than one million $\mathrm{m}^{3}$ ), with a corresponding total optimal operation cost saving from thousands to tens of thousands of RMB, which signifies considerable optimization benefits. The following conclusions were obtained.

(1) Enhanced optimization benefits can be obtained under operation conditions of low daily average heads. The reason is that with the influence of the motor power constraint, the discrete domain of the blade angle at a high pumping head is reduced, leading to a decline in the accuracy of the optimal 
TABLE 2: The evolution situation of relative indexes during successive approximation optimization process.

\begin{tabular}{lcccc}
\hline $\begin{array}{l}\text { Daily average head } \\
(\mathrm{m})\end{array}$ & $\begin{array}{c}\text { Water pumping } \\
\text { load }\end{array}$ & $\begin{array}{c}\text { Saving percentage of MOC } \\
(\%)\end{array}$ & $\begin{array}{c}\text { Reduction of TWPQ } \\
\left(\mathrm{m}^{3}\right)\end{array}$ & $\begin{array}{c}\text { Saving percentage of UMOC } \\
(\%)\end{array}$ \\
\hline \multirow{3}{*}{3.13} & 100 & 0.093 & 2099 & 0.027 \\
& 105 & 0.223 & 2365 & 0.152 \\
\hline \multirow{3}{*}{3.53} & 110 & 0.463 & 1944 & 0.408 \\
& 100 & 0.212 & 3245 & 0.107 \\
\hline \multirow{2}{*}{4.13} & 105 & 0.064 & -233 & 0.071 \\
& 110 & 0.048 & 221 & 0.041 \\
\hline 4.53 & 100 & 0.122 & 88 & 0.119 \\
\hline
\end{tabular}

TABLE 3: Optimal approach scheme of blade angle under typical head and working load.

\begin{tabular}{|c|c|c|c|c|c|c|c|c|c|c|c|c|}
\hline \multirow[t]{2}{*}{$\begin{array}{l}\text { Daily average head } \\
(\mathrm{m})\end{array}$} & \multirow[t]{2}{*}{$\begin{array}{l}\text { Water pumping } \\
\text { load }\end{array}$} & \multirow{2}{*}{$\begin{array}{c}\begin{array}{c}\text { Successive approximation } \\
\text { number }\end{array} \\
1\end{array}$} & \multirow{2}{*}{$\begin{array}{c}\begin{array}{c}\text { Discrete step of blade } \\
\text { angle }\left({ }^{\circ}\right)\end{array} \\
2\end{array}$} & \multicolumn{9}{|c|}{$\begin{array}{l}\text { Optimal approach scheme of blade angle } \\
\text { in each divide time period (period 1-9) }\end{array}$} \\
\hline & & & & 0 & 0 & 4 & 4 & 4 & 2 & 4 & 44 & 4 \\
\hline \multirow[t]{2}{*}{3.13} & \multirow[t]{2}{*}{110} & 2 & 1 & 1 & 1 & 3 & 4 & 4 & 2 & 2 & 44 & 4 \\
\hline & & 3 & 0.5 & 0.5 & 1 & 4 & 4 & 4 & 1 & 3 & 44 & 4 \\
\hline \multirow{3}{*}{4.13} & \multirow{3}{*}{105} & 1 & 2 & 0 & 0 & 2 & 2 & 2 & 0 & 0 & 22 & 2 \\
\hline & & 2 & 1 & -1 & 0 & 2 & 2 & 2 & 0 & 0 & 22 & 2 \\
\hline & & 3 & 0.5 & 0 & 0 & 1.5 & 2 & 2 & -0.5 & 0 & 22 & 2 \\
\hline \multirow{2}{*}{4.53} & \multirow{2}{*}{90} & 1 & 1 & Shutdown & -3 & 0 & 0 & 0 & -2 & -1 & 0 & \\
\hline & & 2 & 0.5 & Shutdown & -4 & 0 & 0 & 0 & -1.5 & 0 & 0 & 0 \\
\hline
\end{tabular}

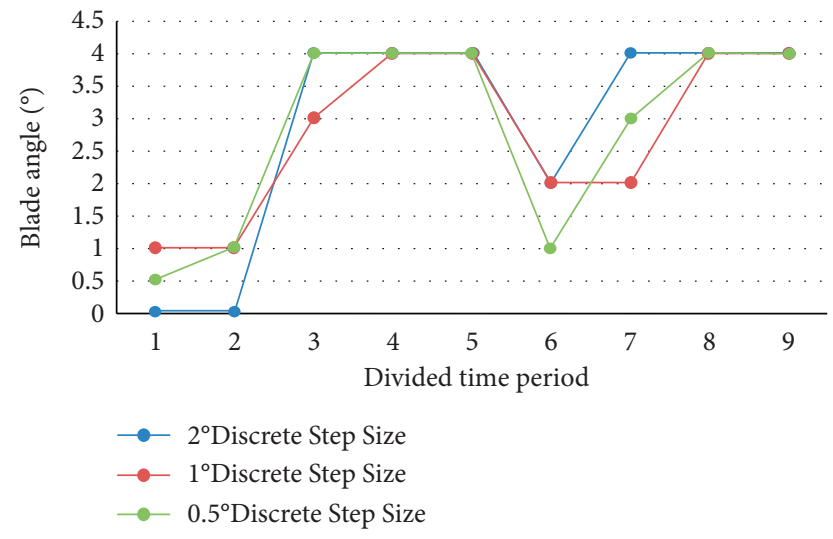

FIGURE 2: Optimization scheme based on successive approximation discretization for blade angles under typical head of $3.13 \mathrm{~m}$ with $110 \%$ load.

TABLe 4: Analysis table of optimal operation benefit under typical operation conditions.

Daily average Water pumping UMOC saving compared with the head $(\mathrm{m})$ load (\%) first time of optimization (\%)

\section{Reduction of actual TWPQ meeting water pumping load $\left(10^{4} \mathrm{~m}^{3}\right)$}

Single unit, Single pumping Single unit, Single pumping 60 days station, 60 days 60 days station, 60 days

\begin{tabular}{lcccccc}
\hline & 100 & 0.027 & 12.59 & 37.78 & 1435.8 & 4307.4 \\
& 105 & 0.152 & 14.19 & 42.57 & 3677.4 & 11032.2 \\
& 110 & 0.408 & 11.66 & 34.99 & 8514.6 & 25543.8 \\
\hline \multirow{3}{*}{3.53} & 100 & 0.107 & 19.47 & 58.41 & 3436.2 & 10308.6 \\
& 105 & 0.071 & -1.40 & -4.19 & 1102.8 & 3308.4 \\
\hline \multirow{2}{*}{4.13} & 110 & 0.041 & 1.33 & 3.98 & 917.4 & 2752.2 \\
\hline 4.53 & 100 & 0.119 & 0.53 & 1.58 & 2098.2 & 6294.6 \\
& 105 & 0.074 & 48.44 & 145.31 & 6177.0 & 18531 \\
\hline
\end{tabular}


value despite having the same successive approximation times compared with the optimal operation at a low daily average head.

(2) Enhanced optimization benefits can be obtained under operation conditions of high operating loads. Affected by peak-valley electricity prices, the pump units can reduce TWPQ to the greatest extent by shutting down in the peak electricity price period, which would decrease the discretization requirements of blade angle and lead to a nonsignificant optimization benefit.

(3) In several typical working conditions, the actual TWPQ obtained from the next instance of optimization could increase compared with the one obtained from the last optimization because this study adopted MOC as the objective function. MOC may decrease with an increase in the actual TWPQ due to the influence of peak-valley electricity prices, which is reasonable (e.g., the combination of daily average head of $3.53 \mathrm{~m}$ with $105 \%$ load shown in Table 2).

\section{Conclusions}

A 1D dynamic programming optimization method based on the discrete control of successive approximation for blade angles was proposed for the optimal operation of a single pump unit with an adjustable blade in an interbasin water transfer pumping station. With this method, the optimization results, including MOC and the corresponding operation schemes of blade angles in each divided time period, can be rapidly and effectively obtained. Remarkable optimization benefits can be realized by using this optimization method compared with the conventional operation under a designed blade angle and constant speed and optimal operation by using traditional $1 \mathrm{D}$ dynamic programming with the blade angle dispersed by only one time.

Meanwhile, reducing the width of the discrete domain of the blade angle through successive optimization ensures that the optimal value of the blade angle in each divided time period is located in the discrete domain, and it can greatly reduce the model solution workload. The proposed optimization method is suitable for the optimal operation of large-scale interbasin water transfer pumping stations with adjustable blades. The case study showed that the method can effectively consider the contradiction between the solution precision and solution workload of the model. Thus, the method can provide a reference for the solution of the same type of models and can enrich optimization theories in system engineering.

Moreover, no remarkable optimization benefit difference was observed in the several times of successive approximation optimization. The reason is that with the influence of the peak-valley electricity price, a large space is provided for the optimal allocation of water quantity in different divided time periods. In the optimization result, blade angle $\theta_{i, \max }$ is usually set in the valley electricity price period, and the shutdown operation is usually set in the peak electricity price period to obtain MOC. In other words, the optimization benefit for successive approximation optimization is the same as that in the other electricity price periods.

Given the limited space, most of the calculation examples in this study involved three successive approximation optimization instances under the same combination of daily average head and water pumping load (the discrete step of the blade angle was set to $0.5^{\circ}$ ). The accuracy of the optimization results can be further improved if the iteration control accuracy is further reduced. Moreover, the optimization benefits would be enhanced under full or super-full operation loads in consideration of peak-valley electricity prices mainly because under nonfull operation loads, the optimal blade angle can be easily obtained in divided time periods with peak or valley prices with minimal successive approximation (maximal blade angle or shutdown), whereas the optimization space of blade angles in periods of nopeak-valley electricity price is limited, leading to an insignificant optimization efficiency.

\section{Data Availability}

Some or all data and models used during the study are available from the corresponding author upon request.

\section{Conflicts of Interest}

All the authors declare that there are no conflicts of interest regarding the publication of this article.

\section{Authors' Contributions}

All the authors contributed to the study conception and design. Material preparation, data collection, and analysis were performed by all authors. The first draft of the manuscript was written by Yi Gong, and all authors commented on previous versions of the manuscript. All authors read and approved the final manuscript.

\section{Acknowledgments}

This work was supported by the 12th Five-Year National Science and Technology Support Project (2015BAB07B01), the 57th Batch of China Postdoctoral Science Foundation Project (2015M571826), Science and Technology Innovation Cultivating Fund of Yangzhou University (2019CXJ071), and Water Conservancy Science and Technology Project of Jiangsu Province (2018045).

\section{References}

[1] L. Zhou, K. Deshpande, X. Zhang, and R. K. Agarwal, "Process simulation of Chemical Looping Combustion using ASPEN Plus for a mixture of biomass and coal with various oxygen carriers," Energy, vol. 195, p. 116955, 2020.

[2] L. Zhou, C. Han, L. Bai, W. Shi, and R. Agarwal, "Numerical and experimental study of multiphase transient core-annular flow patterns in a spouted bed," ASME Journal of Energy Resource Technology, vol. 142, no. 9, Article ID 092104, 2020. 
[3] H. Wang, B. Long, C. Wang, C. Han, and L. Li, "Effects of the impeller blade with a slot structure on the centrifugal pump performance," Energies, vol. 13, no. 7, p. 1628, 2020.

[4] G. Peng, X. Huang, L. Zhou, G. Zhou, and H. Zhou, "Solidliquid two-phase flow and wear analysis in a large-scale centrifugal slurry pump," Engineering Failure Analysis, vol. 114, p. 104602, 2020.

[5] L. Shi, J. Zhu, F. Tang, and C. Wang, "Multi-disciplinary optimization design of axial-flow pump impellers based on the approximation model," Energies, vol. 13, no. 4, p. 779, 2020.

[6] X. He, Y. Zhang, C. Wang et al., "Influence of critical wall roughness on the performance of double-channel sewage pump," Energies, vol. 13, no. 2, p. 464, 2020.

[7] H. L. Wang, B. Long, Y. Yang, Y. Xiao, and C. Wang, "Modelling the influence of inlet angle change on the performance of submersible well pumps," International Journal of Simulation Modelling, vol. 19, no. 1, pp. 100-111, 2020.

[8] L. Shi, W. Zhang, H. Jiao et al., "Numerical simulation and experimental study on the comparison of the hydraulic characteristics of an axial-flow pump and a full tubular pump," Renewable Energy, vol. 153, pp. 1455-1464, 2020.

[9] C. Wang, X. Chen, N. Qiu, Y. Zhu, and W. Shi, "Numerical and experimental study on the pressure fluctuation, vibration, and noise of multistage pump with radial diffuser," Journal of the Brazilian Society of Mechanical Sciences and Engineering, vol. 40 , no. 10 , p. $481,2018$.

[10] L. Zhou, W. Wang, J. Hang, W. Shi, H. Yan, and Y. Zhu, "Numerical investigation of a high-speed electrical submersible pump with different end clearances," Water, vol. 12, no. 4, p. 1116, 2020.

[11] H. Wang, Z. Qian, D. Zhang, T. Wang, and C. Wang, "Numerical study of the normal impinging water jet at different impinging height, based on wray-agarwal turbulence model," Energies, vol. 13, no. 7, p. 1744, 2020.

[12] S. Tang, S. Yuan, and Y. Zhu, "Convolutional neural network in intelligent fault diagnosis toward rotatory machinery," IEEE Access, vol. 8, no. 1, pp. 86510-86519, 2020.

[13] S. Tang, S. Yuan, and Y. Zhu, "Deep learning-based intelligent fault diagnosis methods toward rotating machinery," IEEE Access, vol. 8, no. 1, pp. 9335-9346, 2020.

[14] G. R. Kattel, W. Shang, Z. Wang, and J. Langford, "China's South-to-North water diversion project empowers sustainable water resources system in the north," Sustainability, vol. 11, no. 13, p. 3735, 2019.

[15] G. Fang, X. Zhu, and X. Huang, "Risk analysis of floodwater resources utilization along water diversion project: a case study of the Eastern Route of the South-to-North Water Diversion Project in China," Water Supply, vol. 19, no. 8, pp. 2464-2475, 2019.

[16] M. Mahdi, K. Bryan, "Optimal design and operation of irrigation pumping stations using mathematical programming and Genetic Algorithm (GA)," Journal of Hydraulic Research, vol. 46, no. 2, pp. 237-246, 2008.

[17] J. Cheng, L. Zhang, R. Zhang, and Y. Gong, "Study on optimal day-operation of single adjustable-blade pump unit," Journal of Hydraulic Engineering, vol. 41, no. 4, pp. 499-504, 2010.

[18] K. Kusakana, "Optimal operation scheduling of grid-connected PV with ground pumped hydro storage system for cost reduction in small farming activities," Journal of Energy Storage, vol. 16, pp. 133-138, 2018.

[19] P. Khatavkar and L. W. Mays, "Model for optimal operation of water distribution pumps with uncertain demand patterns," Water Resources Management, vol. 31, no. 12, pp. 3867-3880, 2017.
[20] Y. Zhang, G. Fang, X. Wen, and Y. Tian, "Study on daily optimizing operation of the blade-adjusting of cascade pumping station," Journal of Water Resources and Water Engineering, vol. 28, no. 6, pp. 123-128, 2017.

[21] E. Price and A. Ostfeld, "Discrete pump scheduling and leakage control using linear programming for optimal operation of water distribution systems," Journal of Hydraulic Engineering, vol. 140, no. 6, 2014.

[22] Y. Jiang, L. Xiong, and F. Yao, "Optimization of irrigation water regulation for multistage irrigation pumping system based on two-level coordination model," Transactions of the Chinese Society for Agricultural Machinery, vol. 50, no. 5, pp. 310-319, 2019.

[23] Y. Gong and J. Cheng, "Combinatorial optimization method for operation of pumping station with adjustable blade and variable speed based on experimental optimization of subsystem," Advances in Mechanical Engineering, vol. 6, p. $283520,2014$.

[24] Y. Gong, J. Cheng, R. Zhang, and L. Zhang, "Study of optimal operation method on multiple pump units with adjustableblade for single pumping station based on decompositiondynamic programming aggregation method," Transactions of the Chinese Society for Agricultural Machinery, vol. 41, no. 9, pp. 27-31, 2010.

[25] Y. Makaremi, A. Haghighi, and H. R. Ghafouri, "Optimization of pump scheduling program in water supply systems using a self-adaptive NSGA-II; a review of theory to real application," Water Resources Management, vol. 31, no. 4, pp. 1283-1304, 2017.

[26] M. Dou, J. Zhang, G. Li, and P. Zhao, "A multi-objective water trading optimization model for Henan Province's water-receiving area in the Middle Route of China's Southto-North Water Diversion Project," Water Policy, vol. 21, no. 4, pp. 693-707, 2019.

[27] S. A. Bagloee, M. Asadi, and M. Patriksson, "Minimization of water pumps' electricity usage: a hybrid approach of regression models with optimization," Expert Systems With Applications, vol. 107, pp. 222-242, 2018.

[28] X. Gan, W. Wang, J. Pei, S. Yuan, Y. Tang, and M. K. Osman, "Direct shape optimization and parametric analysis of a vertical inline pump via multi-objective particle swarm optimization," Energies, vol. 13, no. 2, p. 425, 2020.

[29] I. M. Lopez, T. D. Prasad, and B. Paechter, "Ant colony optimization for optimal control of pumps in water distribution networks," Journal of Water Resources Planning and Management, vol. 134, no. 4, pp. 337-346, 2008.

[30] M. Rossi and M. Renzi, "A general methodology for performance prediction of pumps-as-turbines using artificial neural networks," Renewable Energy, vol. 128, pp. 265-274, 2018.

[31] T. Luna, J. Ribau, D. Figueiredo, and R. Alves, "Improving energy efficiency in water supply systems with pump scheduling optimization," Journal of Cleaner Production, vol. 213, pp. 342-356, 2019.

[32] S. Rasoulzadeh-Gharibdousti, M. A. Bozorg Haddad, and M. A. Mariño, "Optimal design and operation of pumping stations using NLP-GA," Proceedings of the Institution of Civil Engineers - Water Management, vol. 164, no. 4, pp. 163-171, 2011.

[33] J. Bohórquez, J. Saldarriaga, and D. Vallejo, "Pumping pattern optimization in order to reduce WDS operation costs," Procedia Engineering, vol. 119, no. 1, pp. 1069-1077, 2015.

[34] A. M. Bagirov, A. F. Barton, H. Mala-Jetmarova et al., "An algorithm for minimization of pumping costs in water 
distribution systems using a novel approach to pump scheduling," Mathematical and Computer Modelling, vol. 57, no. 3-4, pp. 873-886, 2013.

[35] I. P. Kougias and N. P. Theodossiou, "Multiobjective pump scheduling optimization using harmony search algorithm (HSA) and polyphonic HSA," Water Resources Management, vol. 27, no. 5, pp. 1249-1261, 2013.

[36] Y. Jaeeung, W. L. John, and S. Steven, "Dynamic optimal unit commitment and loading in hydropower systems," Journal of Water Resources Planning and Management, vol. 129, no. 5, pp. 388-398, 2003.

[37] M. Saadat and K. Asghari, "Reliability improved stochastic dynamic programming for reservoir operation optimization," Water Resources Management, vol. 31, no. 6, pp. 1795-1807, 2017.

[38] D. Rani, S. Mourato, and M. Moreira, "A generalized dynamic programming modelling approach for integrated reservoir operation," Water Resources Management, vol. 34, no. 4, pp. 1335-1351, 2020.

[39] S. Hang, X. Ai, J. Fang, T. Ding, Z. Chen, and J. Wen, "Realtime optimization of the integrated gas and power systems using hybrid approximate dynamic programming," International Journal of Electrical Power and Energy Systems, vol. 118, p. 105776, 2020.

[40] L. Zhang, J. Cheng, R. Zhang, and Y. Gong, "Optimal operation with variable speed in jiangdu No.4 pumping station based on the theory of dynamic programming with successive approximation," Journal of Irrigation and Drainage, vol. 30, no. 3, pp. 110-113, 2011. 